\title{
LETTER TO EDITOR - THE TREATMENT OF ACUTE POISONING IN CLINICAL EMERGENCY CENTER OF KRAGUJEVAC
}

\author{
Kovacevic Zoran, ${ }^{1}$ Marjanovic Stojanovic Vesna, ${ }^{1}$ Janicijevic Katarina ${ }^{2}$ \\ ${ }^{1}$ Department of Urgent medicine, Clinical Centre of Kragujevac, Kragujevac, Serbia \\ ${ }^{2}$ Department of Social Medicine, Faculty of Medical Sciences, University of Kragujevac, Serbia
}

Primljen/Received 22. 08. 2019. god.

Prihvaćen/Accepted 10. 10. 2019. god.

To the Editor,

All acute poisonings represent urgent conditions in medicine, no matter what clinical features are. Patients with acute poisoning make $3-5 \%$ of the total number of patients treated in emergency medical services „poisoning“, and can be accidental, suicidal and murderous. Making (providing) accurate diagnosis is often difficult because it implies the identification of poison; that is not always possible for auto and heteroanamnesis data, physical examination (checkup) of the patient, and clinical symptoms of poisoning are used for making the diagnosis (1).

A patient with symptoms of acute poisoning is immediately taken in emergency room where the doctor specialist of emergency medicine or the doctor specialist of internal medicine undertakes medical examination which implies: fast estimation of need for respiratory support and mechanical ventilation, or cardiorespiratory reanimation; monitoring of vital functions; measuring of arterial blood pressure, heart rate, arterial oxygen saturation by pulse-oximetry, electrocardiographic record of heart rate, $x$-ray lung recording; consultations with neurologist, surgeon, neurosurgeon, psychiatrist, or if it is necessary with doctors of other specialties; provision of venous line; applying of intravenous saline solution or intravenous sugar solution(dextrose solution); taking blood samples urgently; according to estimation testing blood on methyl-alcohol or ethyl-alcohol, or testing urine on psychoactive substances; estimation of consciousness; identification of signs of external physical injuries; nasogastric intubation in case of acute peroral poisoning except in case of poisoning by corrosive substances (acids, bases) when there are contraindications; this procedure is repeated until the stomach contents are clear and after that activated carbon is given to a patient (2).
If a patient is unconscious, the one needs to be intubated in order to protect the airways. After nasogastric intubation is being done, and after all activated carbon is given to a patient, if a patient is conscious and the collaboration can be established, the vomiting is caused by drinking hot water and after that activated carbon is given to a patient; after initial treatment in resuscitation room patients who are respiratory at risk (affected) of who have disturbances of consciousness are hospitalized in stationary rooms of Clinical Emergency Center, and those who have symptoms of light poisoning are taken in internist ambulance for observation and psychiatrist is consulted about the clinical conditions of them (3).

The poisoning time of observation is estimated on the stabilization of vital parameters, improving the state of consciousness, as well as the development of possible complications depending on the time of ingestion, the type of toxic substance, the time of reporting poisoning to doctors and present co-morbidity. Antidote therapy is used for poisoning in which it is indicated. Atropine ${ }^{\circledR}$ is used for poisoning by organo-phosphates, Naloxane ${ }^{\circledR}$ is used for poisoning by opiates, Aneksat ${ }^{\circledR}$ is used for poisoning by benzodiazepines, ethyl-alcohol is used for poisoning by methyl-alcohol and ethylene-glycol. Measures of extracorporeal detoxification like hemodialysis, hemoperfusion with activated carbon and plasma-pheresis are used in the stationary room of Clinical Emergency Center. Symptomatic and supportive therapy is also used. It is the base in the treatment of all acute poisoning because of a small number of antidotes. Toxic effects of organophosphate insecticides appear because of irreversible inhibition of enzymes of acetyl-cholinesterase which causes accumulating of acetylcholine in the central and peripheral nervous system, and in other tissues and organs. Clinical effects of accumulated acetylcholine are re- 
flected in four clinical syndromes. Acute cholinergic crisis - the most important clinical syndrome that appears after a few minutes, but it also may appear twelve hours after consuming the poison. Effects are classified into three categories: muscarinic, nicotinic and central. Muscarinic effects are represented by intensified bronchial secretion, bronchial spasm, intensified perspiration, hypersalivation, lacrimation, incontinence of urine and feces, sickness and vomiting, bradycardia, hypotension, and myosis. Nicotinic effects are shown by muscular fasciculation, spasms, paralyzation of diaphragm, areflexia, respiratory insufficiency, hypertension, tachycardia and pupil dilation. Effects by CNS are anxiety, headache, tremor, confusion, convulsion, and depression of the respiratory system. The intermediate syndrome - neurology signs that are shown in the period of 24 to 96 hours after acute cholinergic crisis (muscular weakness of neck flexor; respiratory muscles, as well, as muscles of extremities dominant; delayed peripheral neuropathy, lesions of other organs). Every single patient who has been poisoned by chemical compounds of the group of organophosphate insecticides is attended by the aforementioned protocol for acute poisoning (4).

If the clinical status of the patient is specific, there is a possibility of taking the patient's blood and sending it for analyzes in the Toxicology Lab of Military Medical Academy in Belgrade. If it is possible, take biological material (urine, blood, lavage) for proving (substantiating) the poison and its metabolites (that could be important as a piece of evidence at the court). Specific therapy for these poisonings means giving of: Atropine $\mathbb{B}$ in

\section{REFERENCES}

1. Saxena K, Kingston R. Acute poisoning: management protocol. Postgrad Med. 1982; 71(5): 67-77.

2. Poisoning-acute guidelines for initial management. Austin Hospital Heidelberg Repatriation, Hospital Royal Talbot Rehabilitation Centre \& Research Centre, Austin Health Victoria, Publ, 2019.

3. Wu YX, Zhao GJ, Hong GL, Li MF, Li D, Wu B, et al. Clinical analysis of 22 cases of a syndrome caused by acute poi- the dosage of 1 to $2 \mathrm{mg}$ intravenously on every five minutes until the signs of hyper-atropinisation (dry lungs, dryness of skin and mouth, tachycardia, face(flushing) redness, mydriasis with decreasing dosage in correlation with the clinical features, so far signs of cholinergic crisis exist; reactivators (actifiers) of cholinesterase (compounds of the group of oximes-pralidoxime in the dosage of $1 \mathrm{~g}$ intravenously or intramuscularly in the salt solution on every 4 to 6 hours during the first 48 hours, and it is usually given to a patients for seven days); Diazepam ${ }^{\circledR}$ (anticonvulsants in dosage of $10 \mathrm{mg}$ in every 8 hours intravenously whose purpose is preventing convulsion effect of accumulated acetylcholine); symptomatic and supportive therapy (correction of acid-base and electrolyte imbalance) (5).

The role of hemodialysis in acute poisoning has repented as an indispensable treatment for acute poisoning today (6).

\section{Acknowledgments}

No funding is used for the present work. All authors contributed equally and were involved in writing the paper and finally approved the submitted and published versions without any conflict of interest.

Conflict of Interests: The authors declare that there are no conflicts of interest related to this article.

\section{Licensing}

This work is licensed under a Creative Commons Attribution 4.0 International (CC BY 4.0) License.

soning. Zhonghua Lao Dong Wei Sheng Zhi Ye Bing Za Zhi. 2019; 37(2): 136-8

4. Hackl G. Acute intoxications: markers for screening, diagnosis and therapy monitoring. Med Klin Intensivmed Notfmed. 2019; 114(4): 302-12.

5. Lam SW, Engebretsen KM, Bauer SR. Toxicology today: what you need to know now. J Pharm Pract. 2011; 24(2): 174-88.

6. Chibishev A, Petkovska L, Tozija L, Zdravkovska M, Shikole E. The role of hemodialysis in the treatment of acute acetic acid poisonings. Int J Artif Organs. 2017; 40(5): 219-23.

\section{Correspondence to/Autor za korespondenciju}

dr Zoran Kovacevic

Department of Urgent medicine, Clinical Centre of Kragujevac, Kragujevac, Serbia

Zmaj Jovina 30, 34000 Kragujevac, Serbia,

e-mail: zoki_med@ptt.rs

Tel:+381 628245343 